\title{
Análise de seis sistemas de recolhimento do palhiço na colheita mecânica da cana-de-açúcar
}

\author{
Marcio B. Michelazzo ${ }^{1} \& 0$ scar A. Braunbeck ${ }^{1}$
}

\section{RESU M O}

A biomassa da cana-de-açúcar é uma das fontes de energia renovável mais disponível no Brasil, em virtude dos seus resíduos de colheita, como pal hiço (pontas e folhas); todavia, 0 aproveitamento do palhiço em larga escala é dificultado pelo alto custo de sua recuperação, sobretudo no que diz respeito ao recolhimento, adensamento e transporte. Com o presente trabalho, apresenta-se uma análise dos processos envolvidos na recuperação do palhiço, como densidade final do palhiço e princípios operacionais das máquinas envolvidas, juntamente com uma análise econômica, através de um modelo de cálculo de custo, por meio de simulação de rendimentos e capacidades operacionais que compõem cada sistema de recuperação do palhiço. Seis sistemas foram avaliados, técnica e economicamente. De acordo com os resultados, o sistema de colheita integral apresentou o menor custo de recuperação do palhiço para qualquer distância, seguido dos sistemas picado a granel, fardo cilíndrico, fardo algodoeiro, peletização e briquetagem.

Palavras-chave: biomassa, colheita, enfardamento, palha

\section{Analysis of six systems of trash recovery in mechanical harvesting of sugarcane}

\begin{abstract}
Sugarcane biomass is one of the energy sources most readily available in Brazil, mainly due to residues such as trash (tops, dry and green leaves). Large scale use of these residues still faces high recovery costs related to gathering, baling, transportation, chopping and residue utilization technology. An analysis was done of the mechanical principles involved in the packing processes. A model was defined to estimate the cost of trash recovery, simulating the field capacity, oil consumption, depreciation, repair and maintenance as well as labor required for the field and transport operations. Six recovery systems were studied both from the technical and economical points of view. The results show ed that handling billets and trash together, described as "Integral harvesting", has the lowest cost for trash recovery, both for short and long distances, followed by bulk handling of chopped trash, the round bale, the cotton bale and finally the pellet and briquette systems.
\end{abstract}

Key words: biomass, harvesting, baling, cane residues 


\section{INTRODUÇÃO}

A biomassa se destaca, entre as diferentes fontes renováveis de energia, por ser altamente disponível no Brasil. Biomassa é definida, por Wood \& Hall (1995) como resíduos de origem orgânica que não foram fossilizados mas têm possibilidade de serem utilizados como combustível. Goldemberg \& Coelho (2000) afirmam que o Brasil tem enorme potencial para geração de energia através do uso de resíduos agrícolas que atualmente são deixados no solo. No caso da cana, quando não há realização de queimadas como práticas de précolheita, existe a possibilidade de se aproveitar o palhiço, que é composto basicamente por pontas, palha, folhas verdes, frações de colmos e raízes, segundo Ripoli \& Ripoli (2004).

Com o grande potencial de que se dispõe, o palhiço pode ser empregado como fonte energética; todavia, seu aproveitamento em larga escala ainda é dificultado pelos altos custos de sua recuperação, que envolve recolhimento, adensamento, transporte, redução de tamanho e tecnologia para utilização na planta industrial. Existem dificuldades também relacionadas com a heterogeneidade e baixa densidade do material, além de se utilizar, atualmente, equipamentos de baixa capacidade operacional e custos elevados, por serem equipamentos adaptados para colheita de forragens.

A compactação desses resíduos é de importância fundamental para diminuição dos custos de transporte. Eriksson \& Prior (1990) citam três sistemas de adensamento de alta pressão: rosca extrusora, peletização e briquetagem.

Segundo Schembri et al. (2002) poder-se-á duplicar a quantidade de matéria-prima para geração de energia, colhendo-se a cana inteira e crua, com separação posterior do palhiço na usina; os autores desenvolveram um protótipo de equipamento para separação do palhiço da cana com capacidade $150 \mathrm{Mg} \mathrm{h}^{-1}$, recuperando-se de 91 a $95 \%$ do palhiço e com menos de $1 \%$ de perdas de cana.

Destaca-se que o transporte integral da cana, juntamente com o palhiço, resulta em menor densidade de carga o que obrigaria a se usar carrocerias com dimensões maiores. $\mathrm{O}$ volume e o peso dos veículos de transporte estão limitados pela Resolução no 12/98 do CONTRAN (1998). O peso bruto total pode atingir no máximo $45 \mathrm{Mg}$ por veículo, com dimensões limitadas na largura, o comprimento e a altura do veículo.

Visa-se com este trabalho, efetuar análise comparativa de seis sistemas de manuseio do palhiço, desde a colheita até a entrega, na esteira da usina. A análise proposta se baseia no desenvolvimento e utilização de um modelo que permite simular os rendimentos, assim como os custos globais e detalhados das operações que compõem cada sistema.

\section{MATERIAL E MÉTODOS}

\section{Máquinas}

Nesta análise comparativa dos sistemas de recuperação de palhiço foram avaliados as diversas operações e seus respectivos parâmetros operacionais. O material considerado no estudo envolve, fundamentalmente, máquinas para a colheita, enleiramento, recolhimento, adensamento, carregamento, transporte e redução de tamanho do palhiço, segundo a relação da Tabela 1.

Tabela 1. Máquinas empregadas nos sistemas simulados

\begin{tabular}{|c|c|}
\hline Máquinas & Função \\
\hline Trator & $\begin{array}{c}\text { Acionamento de enleiradora, enfardadora, transbordos e } \\
\text { prensa }\end{array}$ \\
\hline Enfardadora & Recolhimento e adensamento do palhiço \\
\hline $\begin{array}{l}\text { Enleiradora } \\
\text { Forrageira } \\
\text { Carregadora }\end{array}$ & $\begin{array}{l}\text { Enleiramento do palhiço esparramado no solo } \\
\text { Recolhimento e redução do tamanho do palhiço } \\
\text { Carregamento e descarregamento dos fardos }\end{array}$ \\
\hline Transbordo & $\begin{array}{l}\text { Carretas teladas basculantes para transporte interno do } \\
\text { palhiço }\end{array}$ \\
\hline "Bass boy" & $\begin{array}{l}\text { Transbordo com esteira dosadora para abastecimento } \\
\text { da prensa }\end{array}$ \\
\hline Transmódulo & Trans porte do fardo gigante \\
\hline Caminhão & Trans porte externo do palhiço \\
\hline Prensa de algodão & Adensamento do palhiço \\
\hline Triturador estacionário & Fragmentação dos fardos grandes \\
\hline Briquetadora & Adensamento do palhiço \\
\hline Peletizadora & Adensamento do palhiço \\
\hline Estação de limpeza & Separação entre o palhiço e os rebolos \\
\hline
\end{tabular}

\section{Sistemas}

O palhiço é liberado pelas colhedoras na forma de uma camada espalhada sobre a superfície do solo com espessura bastante desuniforme. Ele é deixado no solo para secagem por aproximadamente 10 dias, o que resulta em uma umidade pouco maior que $20 \%$ em média (variando de cerca de 15 a 30\%), segundo Ripoli (2002); após este período de secagem natural, considerou-se que o palhiço foi enleirado com apenas uma passada da enleiradora, visando reduzir a contaminação com terra. Este material enleirado é, posteriormente, recolhido, de acordo com o sistema a ser utilizado.

As características gerais dos diferentes sistemas de recuperação do palhiço, considerados neste trabalho, estão apresentadas sucintamente, a seguir:

a) Fardo grande: depois de enleirado, o palhiço é recolhido pela enfardadora que realiza uma prensagem de baixa pressão, com amarração, utilizando-se mecanismo biela-manivela ou de rolo (adotado nesta simulação). Os fardos são liberados pela enfardadora e permanecem no campo para serem carregados e transportados até o pátio de armazenamento. No momento da queima, os fardos são picados para facilitar a alimentação e combustão na caldeira.

b) Picado a granel: as leiras são recolhidas pela picadora de forragem, a qual reduz o tamanho do palhiço para aproximadamente $1 \mathrm{~cm}$, lançando-o pelo princípio de transporte inercial até o transbordo, que carrega os caminhões e transportam o palhiço picado até o pátio de armazenamento, perto das caldeiras.

c) Briquetado: o palhiço enleirado é levantado pela picadora de forragens e lançado, pelo princípio de transporte inercial ao transbordo que alimenta diretamente no campo as prensas briquetadoras. Elas efetuam uma prensagem de alta pressão, sem amarração, utilizando mecanismo biela- 
manivela. Depois de adensado o palhiço, na forma de briquetes, é transportado até a usina, por caminhões.

d) Peletizado: este caminho de recuperação de palhiço equivale ao de briquetagem descrito acima, mudando apenas na configuração da prensa, que utiliza um processo de adensamento contínuo, através de rolos que comprimem e forçam a passagem do material através de uma matriz perfurada, com pressão de adensamento suficiente para provocar a coesão das fibras, não sendo necessário o uso de amarração.

e) Fardo algodoeiro: a leira de palhiço é recolhida pela picadora de forragem com lançamento pelo princípio de transporte inercial até o transbordo; em seguida, o transbordo alimenta a prensa de algodão no campo. A prensa opera em um processo intermitente de adensamento de baixa pressão, por meio de pistões hidráulicos, em unidades estacionárias, sem amarração de fardo. O transporte é feito através de caminhão basculante especial (roll-on/roll-off).

f) Integral: neste sistema, diferentemente dos anteriores, o palhiço é colhido juntamente com os rebolos; com a colhedora operando com seus extratores desligados. A cana e o palhiço misturados são lançados até o transbordo, que os conduz até o caminhão que, por sua vez, faz o transporte desse material até a usina onde são separados em uma unidade de limpeza a seco, envolvendo separação pneumática e mecânica com discos poligonais rotativos.

Para as simulações considerou-se, neste trabalho, um período anual de uso das máquinas de 210 dias (UNICA, 2003), com aproveitamento de $85 \%$ dos dias úteis de operação (Lopes, 1995). A quantidade de palha deixada no campo após a colheita foi considerada de $20 \mathrm{Mg} \cdot \mathrm{ha}^{-1}$. Estimou-se uma taxa de retirada de $50 \%$, semelhante à citada por Macedo \& Cortez (2000) e Ripoli (2002). A vida útil e os valores de aquisição e residual das máquinas foram determinados por meio de catálogos de fabricantes e contatos pessoais com revendedoras. As características do palhiço adensado, encontradas por vários autores, estão relacionadas na Tabela 2 .

Tabela 2. Características do palhiço adensado nos diferentes sistemas

\begin{tabular}{lcccc}
\hline \multirow{2}{*}{ Características } & \multicolumn{4}{c}{ Sistemas } \\
\cline { 2 - 5 } & $\begin{array}{c}\text { Fardo } \\
\text { cilíndrico }^{(1)}\end{array}$ & $\begin{array}{c}\text { Fardo } \\
\text { algodoeiro }^{(2)}\end{array}$ & Briquetagem $^{(3)}$ & Peletização $^{(3)}$ \\
\hline Densidade $\left(\mathrm{kg} \mathrm{m}^{-3}\right)$ & 170 & 160 & 1.000 & 1200 \\
Densidade & - & - & 500 & 600 \\
aparente $\left(\mathrm{kg} \mathrm{m}^{-3}\right)$ & 231 & 10.000 & 2,4 & 0,01 \\
Peso $(\mathrm{kg})$ & 1,36 & 62,5 & 0,002 & 0,00001 \\
Volume $\left(\mathrm{m}^{3}\right)$ & - & 2,5 & - & - \\
Altura $(\mathrm{m})$ & - & 2,5 & - & - \\
Largura $(\mathrm{m})$ & 1,2 & 10 & 0,30 & 0,035 \\
Comprimento $(\mathrm{m})$ & 1,2 & - & 0,10 & 0,01 \\
Diâmetro $(\mathrm{m})$ & &
\end{tabular}

(1) Rípoli (2002) (2) Ideanews (2002) ${ }^{(3)}$ COPERSUCAR (1983)

\section{Tempo de trabalho}

O rendimento dos equipamentos foi calculado após estimativas dos seguintes tempos de trabalho, através de contatos pessoais com as usinas.

Tempo produtivo (Tprod): é o tempo em que a máquina está efetivamente realizando sua função produtiva.

Tempo auxiliar (Taux): corresponde ao tempo que a má- quina utilizou para realizar funções auxiliares necessárias à função produtiva (motor funcionando), porém sem que ela realize efetivamente, sua função produtiva.

Tempo perdido (Tperd): é o período em que a máquina estava disponível e apta para efetuar sua função produtiva mas não foi utilizada em função de situações gerenciais.

Tempo manutenção (Tmanut): são as horas usadas para efetuar manutenções da máquina, tanto preventivas quanto corretivas.

Jornada diária de trabalho (Jtrab): é a somatória dos tempos produtivo, auxiliar, perdido e de manutenção.

\section{Eficiência}

Após as estimativas dos tempos, efetuou-se o calculo das eficiências. A eficiência geral do sistema de recolhimento do palhiço pode ser dividida em quatro componentes principais, associadas às características intrínsecas da operação que envolvem as características da área agrícola, do gerenciamento, da própria máquina e das determinações administrativas da direção da empresa.

Eficiência operacional $\left(\mathrm{Ef}_{\mathrm{o}}\right)$ : é a relação entre o tempo em que a máquina está desempenhando efetivamente sua função produtiva (neste caso, processando o palhiço), e o tempo total em que a máquina permaneceu em operação, incluindo os tempos auxiliares, que são aqueles necessários para a realização da operação, mas que, durante os quais, não existe processamento efetivo de palhiço como, por exemplo, manobras de cabeceiras, desembuchamentos, deslocamentos entre talhões etc., é dada pela Eq. 1:

$$
E f_{0}=\frac{T_{\text {prod }}}{T_{\text {prod }}+T_{\text {aux }}} \cdot 100
$$

Eficiência de utilização $\left(\mathrm{Ef}_{\text {util }}\right)$ : corresponde à relação entre o tempo em que a máquina esteve efetivamente em funcionamento e o período em que ela estava disponível, porém não sendo utilizada, dada pela Eq. 2. Os tempos perdidos correspondem a situações gerenciais do sistema, que independem da máquina, por exemplo, paradas da carregadora ou da colhedora por falta de transporte, paradas por chuva, falta de programação sobre a próxima área a ser processada etc.

$$
\mathrm{Ef}_{\mathrm{util}}=\frac{\mathrm{T}_{\text {prod }}+\mathrm{T}_{\text {aux }}}{\mathrm{T}_{\text {prod }}+\mathrm{T}_{\text {aux }}+\mathrm{T}_{\text {perd }}} \cdot 100
$$

Eficiência de disponibilidade $\left(\mathrm{Ef}_{\mathrm{d}}\right)$ : refere-se à relação entre o tempo em que a máquina esteve disponível para operar e às horas da jornada diária de trabalho, que inclui o tempo necessário para a manutenção da máquina e durante o qual não está disponível para operar.

$$
E f_{\text {disp }}=\frac{T_{\text {prod }}+T_{\text {aux }}+T_{\text {perd }}}{T_{\text {prod }}+T_{\text {aux }}+T_{\text {perd }}+T_{\text {man }}} \cdot 100
$$

Eficiência de aproveitamento $\left(\mathrm{Ef}_{\mathrm{a}}\right)$ : diz respeito à relação entre a jornada de trabalho e às $24 \mathrm{~h}$ do dia, Eq. 4; ela é determinada pela direção da empresa, em função, fundamentalmente, das condições de luminosidade, aspectos legais re- 
lacionados a mão-de-obra, segurança, qualidade das operações, capacidade de investimento em máquinas e sazonalidade das operações. Nesta simulação, a jornada de trabalho foi considerada de $24 \mathrm{~h}$.

$$
\mathrm{Ef}_{\text {aprov }}=\frac{\mathrm{J}_{\text {trab }}}{24} \cdot 100=\frac{\mathrm{T}_{\text {prod }}+\mathrm{T}_{\text {aux }}+\mathrm{T}_{\text {perd }}+\mathrm{T}_{\text {man }}}{24} \cdot 100
$$

Eficiência geral $\left(\mathrm{Ef}_{\text {geral }}\right)$ : representa a parte das 24 horas do dia, em que a máquina está efetivamente desempenhando sua função produtiva e corresponde ao produto das quatro eficiências descritas acima.

$$
E f_{\text {geral }}=E f_{a} \times E f_{d} \times E f_{u} \times E f_{d}=\frac{T_{\text {prod }}}{24} \cdot 100
$$

Uma vez determinadas as componentes da eficiência geral, é possível identificar os setores da empresa que maior peso têm no desempenho do sistema, permitindo alertar para a necessidade de se melhorar eficiências baixas com potencial de aprimoramento (Nuñez Gago, 1986; Fernandes, 2000).

\section{Capacidade}

Capacidade de campo teórica (Cct): representa a quantidade teórica de palhiço que a máquina conseguiria processar por unidade de tempo se o funcionamento fosse ininterrupto, expressa em toneladas de palhiço processado por hora.

Capacidade de campo efetiva (Cef): é o trabalho real que a máquina realizou, também expressa em toneladas de palhiço processado por hora, mas corrigida pela eficiência geral, conforme a Eq. 6:

$$
\text { Cef }=\operatorname{Cct} \cdot \frac{E_{\text {geral }}}{100}
$$

\section{Custo}

Uma vez determinada a capacidade efetiva de cada operação, foi possível encontrar os custos do palhiço recolhido, expressos em $\mathrm{R} \$ \mathrm{Mg}^{-1}$. Eles são compostos de: despesas com manutenção e mão-de-obra; gastos com taxas e garagem, seguros; combustível e lubrificantes; depreciação das máquinas e, por fim, custo do capital.

\section{Outras análises}

Para a simulação foi considerado um caminhão tipo "Romeu e Julieta". Analisou-se, também, a capacidade de carga do caminhão levando-se em consideração a Resolução 12/98 do CONTRAN (1998), o consumo de combustível e o custo de transporte. A capacidade de carga do caminhão está relacionada com a carga efetiva, que é a carga que o veículo transporta realmente. Como visto na Eq. 7, ela varia de acordo com o grau de adensamento do palhiço atingido nos diversos sistemas e com a capacidade volumétrica dos caminhões.

$$
\text { CargaEf }=\frac{\mathrm{VC} \cdot \mathrm{MEp}}{1000}
$$

sendo:

CargaEf $=$ carga efetiva, $\mathrm{Mg}$
$\mathrm{VC}=$ capacidade volumétrica do transporte; $\mathrm{m}^{3}$

MEp = massa específica do palhiço; $\mathrm{kg} \mathrm{m}^{-3}$

Efetuou-se ainda uma análise de sensibilidade do custo a cada parâmetro envolvido nos sistemas de recolhimento, acrescendo em $1 \%$ seu valor e quantificando a variação de custo resultante desta variação.

\section{RESULTADOS E DISCUSSÃO}

Para todas as simulações efetuadas foram considerados parâmetros correspondentes a rendimentos altos, que se relacionariam a sistemas consolidados operando próximos de sua máxima eficiência.

\section{Capacidade de carga}

A influência da densidade do material sobre a carga transportada pode ser vista na Tabela 3 para os sistemas de recuperação do palhiço em estudo. Apesar do volume de carga ser o mesmo para todos os sistemas, a carga transportada varia drasticamente de um sistema para outro.

Tabela 3. Desempenho do transporte em cada sistema

\begin{tabular}{lcccccc}
\hline & \multicolumn{6}{c}{ Sistemas } \\
\cline { 2 - 7 } Parâmetros & $\begin{array}{c}\text { Picado } \\
\text { a } \\
\text { granel }\end{array}$ & $\begin{array}{c}\text { Fardo } \\
\text { algodo } \\
\text { eiro }\end{array}$ & $\begin{array}{c}\text { Fardo } \\
\text { cilíndrico }\end{array}$ & Briquetagem & Peletização & $\begin{array}{c}\text { Colheita } \\
\text { integral }\end{array}$ \\
\hline Carga efetiva $^{1}$ & 6 & 10 & 11,5 & 35 & 35 & 28 \\
Viagens $^{2}$ & 156 & 100 & 87 & 29 & 29 & 36 \\
Caminhões $^{3}$ & 18 & 9 & 9 & 3 & 3 & 5 \\
\hline
\end{tabular}

${ }^{1}$ Carga efetiva $(\mathrm{Mg})$ do caminhão para uma capacidade volumétrica da carga de $80 \mathrm{~m}^{3}$

${ }^{2}$ Número de viagens realizadas pelos caminhões nos sistemas, para transportar $1000 \mathrm{Mg} \mathrm{dia}^{-1}$

${ }^{3}$ Quantidade de caminhões para transportar $1000 \mathrm{Mg} \mathrm{dia}^{-1}$

Como a Resolução 12/98, do CONTRAN restringe o comprimento, a largura e a altura de um veículo que trafega nas rodovias públicas, o volume útil fica reduzido, deste modo, a aproximadamente $80 \mathrm{~m}^{3}$.

No caso do sistema de recolhimento picado a granel, não existe adensamento mecânico, por isso o fator que limita a capacidade de carga dos veículos de transporte é o volume da carga. Pois o tamanho da carga, relativo às $45 \mathrm{Mg}$ permitidas pela lei, ultrapassaria o limite das dimensões estabelecido pelo CONTRAN. Portanto, neste sistema o peso da carga transportada, com o volume dentro do limite, não alcança o peso bruto máximo permitido por lei. O caminhão é, então, subutilizado, sendo necessário um número maior de viagens e, consequientemente, maior quantidade de caminhões, como visto na Tabela 3.

No sistema de fardo algodoeiro, o fardo resultante do adensamento apresenta dimensões grandes $(2,5 \times 2,5 \times 10 \mathrm{~m})$, razão pela qual se transporta apenas um fardo por vez e, conseqüentemente, o caminhão, também é subutilizado necessitando realizar mais viagens.

Para o sistema de fardo cilíndrico, como nos sistemas anteriores, o número elevado de viagens também é explicado pelo fato de que o peso da carga transportada é inferior 
ao peso bruto total permitido por lei, resultando em subutilização do caminhão. Visto que para ao se atingir o peso permitido, as dimensões da carga ultrapassariam o permitido por lei.

Por outro lado, nos sistemas de alta pressão (peletização e briquetagem) a densidade alcançada é alta e, neste caso, o peso passa a ser o fator limitante pela lei da balança, visto que ao se preencher o volume permitido pelo CONTRAN, o peso ultrapassaria o valor permitido.

\section{Investimento}

A Figura 1 mostra uma estimativa do montante de investimentos necessários em máquinas para se processar 1.000 $\mathrm{Mg}$ de palhiço por dia.

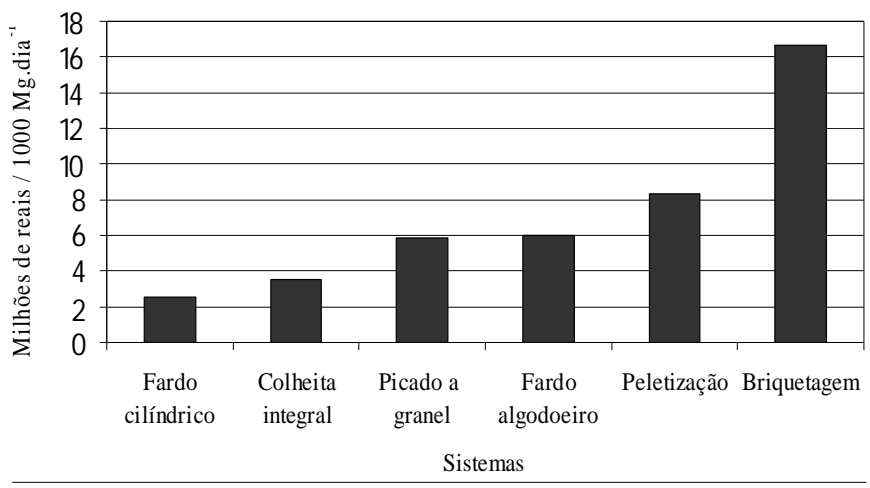

Figura 1. Estimativa da demanda de investimento para as operações envolvidas na recuperação do palhiço (milhões de reais/1.000 $\mathrm{M} \mathrm{g} \mathrm{dia}^{-1}$ )

Para o sistema Integral o investimento foi de cerca de 3,5 milhões de reais, visto que sua maior demanda está relacionada à estação de limpeza, que apesar de ter grande capacidade (aproximadamente $2.000 \mathrm{Mg} \mathrm{dia}^{-1}$ ) apresenta alto custo de implementação, próximo de 6 milhões de reais; todavia, o valor do investimento neste sistema está, de modo geral, entre os mais baixos, pois não é preciso adquirir novos equipamentos, como transbordos, caminhões, colhedoras etc., uma vez que se aproveita o maquinário já utilizado pela cana.

Já os sistemas que utilizam peletização e briquetagem foram os que apresentaram maiores investimentos, decorrente do fato da peletizadora e briquetadora serem máquinas de baixa capacidade operacional, em torno de $50 \mathrm{Mg} \mathrm{dia}^{-1}$, tornando-se oportuno, adquirir-se maior número de máquinas para se processar o palhiço.

\section{Custo total}

O custo total do palhiço em três distâncias de recuperação $(15,50$ e $100 \mathrm{~km})$ pode ser visto na Figura 2.

Pode-se observar que o sistema Integral apresentou o menor custo, de 12,65 $\mathrm{R} \$ \mathrm{Mg}^{-1}$, sendo pouco influenciado pela distância de transporte. Ressalta-se, que no sistema de colheita integral, a colheita da cana é realizada simultaneamente com o recolhimento do palhiço e, assim, o custo final acaba sendo dividido entre a cana e o palhiço. Portanto, para o cálculo do custo de recuperação por este sistema considerou-se a porção referente apenas ao palhiço, que representa

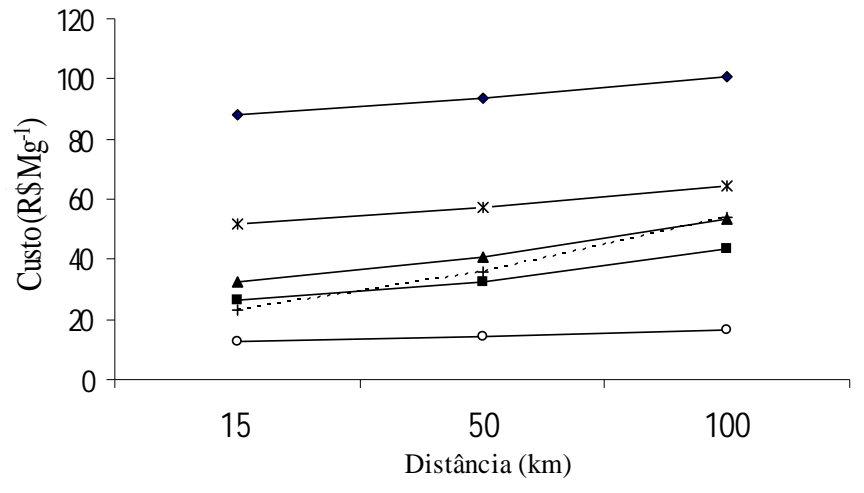

$\begin{array}{lll}\longrightarrow-\text { Briquetagem } & -*-\text { Peletização } & \longrightarrow \text { Fardo algodoeiro } \\ \cdots+\cdots \text { Picado a granel } & \longrightarrow \text { Fardo cilíndrico } & - \text { Colheia integral }\end{array}$

Figura 2. Estimativa do custo total do palhiço recuperado nos vários sistemas, em três distâncias (15, 50 e 100 km)

$20 \%$ da carga transportada (Nery, 2000; Leon, 2000).

O sistema picado a granel teve custo de $23,34 \mathrm{R} \$ \mathrm{Mg}^{-1}$. Seu custo final foi o mais influenciado pela distância de transporte em que o aumento no custo do transporte ocorre principalmente em função da baixa densidade do material, o que aumenta o número de viagens e, conseqüentemente, o consumo de combustível e os investimentos necessários para disponibilizar um número maior de veículos transportadores.

Os sistemas de adensamento de alta pressão apresentaram os maiores custos, como consequiência da baixa capacidade das máquinas adensadoras, o que resulta em maior consumo de combustível e também maior necessidade de investimento em maquinário.

\section{Análise de sensibilidade}

No sistema de fardo cilíndrico o custo de recuperação do palhiço foi mais influenciado positivamente pela corda de amarrar o fardo, sobretudo pela quantidade de corda utilizada (cerca de $250 \mathrm{~g}$ por fardo) e por seu valor unitário (por volta de $9,00 \mathrm{R} \$ \mathrm{~kg}^{-1}$ de corda). O custo da corda é de cerca de $10,00 \mathrm{R} \$ \mathrm{Mg}^{-1}$ de palhiço enfardado, representando quase $40 \%$ do custo total do enfardamento.

Como pode ser visto na tabela 4, para o sistema de palhiço picado a granel, o parâmetro que mais onerou o custo de recuperação do palhiço, quando seu valor foi acrescido em $1 \%$, foi o valor de aquisição das máquinas, com $0,5 \%$ de aumento no custo final de recuperação e nele se observa que a sensibilidade apresentada pelo valor de aquisição das máquinas é explicada pelo fato da necessidade de se adquirir maior número de transbordos e caminhões, visto que a carga efetiva é baixa.

O valor de aquisição das máquinas no sistema de colheita integral, também foi o parâmetro responsável pelo maior aumento do custo final de recuperação do palhiço, aumentando o custo final em $0,7 \%$. Mesmo com o aproveitamento da frota da colheita da cana, este parâmetro foi influenciado, sobretudo, pela elevada demanda de investimento pela construção da estação de limpeza, cerca de 6 milhões de reais.

Tanto para o sistema de briquetagem quanto para o de 
Tabela 4. Variação no custo final de recuperação do palhiço pelo sistema de fardo cilíndrico, quando cada parâmetro é acrescido individualmente em $1 \%$ do seu valor

\begin{tabular}{|c|c|c|c|c|c|c|}
\hline Parâmetros & $\begin{array}{c}\text { Fardo } \\
\text { cilíndrico }\end{array}$ & $\begin{array}{c}\begin{array}{c}\text { Picado a } \\
\text { granel }\end{array} \\
\end{array}$ & $\begin{array}{c}\text { Fardo } \\
\text { algodoeiro }\end{array}$ & $\begin{array}{l}\text { Colheita } \\
\text { integral }\end{array}$ & Briquetagem & Peletização \\
\hline & \multicolumn{6}{|c|}{ Variação (\%) } \\
\hline $\begin{array}{l}\text { Corda de } \\
\text { amarrar o } \\
\text { fardo }\end{array}$ & $0,4^{(1)}$ & - & - & - & - & - \\
\hline $\begin{array}{l}\text { Valor de } \\
\text { aquisição } \\
\text { das } \\
\text { máquinas }\end{array}$ & 0,3 & 0,5 & 0,5 & 0,7 & 0,5 & 0,5 \\
\hline $\begin{array}{l}\text { Preço de } \\
\text { combustível }\end{array}$ & 0,2 & 0,3 & 0,3 & 0,04 & 0,4 & 0,4 \\
\hline $\begin{array}{l}\text { Tempo } \\
\text { perdido }\end{array}$ & 0,1 & 0,3 & 0,3 & 0,2 & 0,2 & 0,3 \\
\hline $\begin{array}{l}\text { Distância } \\
\text { de } \\
\text { transporte }\end{array}$ & 0,1 & 0,2 & 0,1 & 0,05 & 0,02 & 0,04 \\
\hline $\begin{array}{l}\text { Densidade } \\
\text { da carga do } \\
\text { caminhão }\end{array}$ & $-0,1$ & $-0,2$ & $-0,1$ & $-0,03$ & $-0,02$ & $-0,03$ \\
\hline $\begin{array}{l}\text { Capacidade } \\
\text { de campo } \\
\text { teórica }\end{array}$ & $-0,5$ & $-1,1$ & $-1,0$ & $-0,7$ & $-1,2$ & $-1,0$ \\
\hline $\begin{array}{l}\text { Eficiência } \\
\text { geral }\end{array}$ & $-0,5$ & $-1,1$ & $-1,0$ & $-0,8$ & $-1,0$ & $-1,0$ \\
\hline $\begin{array}{l}\text { Jornada de } \\
\text { trabalho }\end{array}$ & $-0,8$ & $-1,8$ & $-1,7$ & $-1,2$ & $-1,5$ & $-1,6$ \\
\hline
\end{tabular}

(1) Apenas este sistema apresenta esse parâmetro

peletização, o valor de aquisição das máquinas e o preço do combustível foram os parâmetros que mais tiveram influência no aumento dos custos. Em ambos os sistemas estes parâmetros influenciaram de forma positiva, respectivamente em 0,5 e $0,4 \%$, o custo final quando se aumentou $1 \%$ dos seus valores, individualmente; isto ocorre em virtude das máquinas serem de alto valor agregado, apresentarem elevada demanda por combustível para seu acionamento e serem equipamentos de baixa capacidade.

Por outro lado, em todos os sistemas a jornada de trabalho foi, sem exceção, o parâmetro que mais contribuiu para a redução dos custos de recuperação, demonstrando a importância de se trabalhar com máxima jornada diária. A capacidade potencial e a eficiência geral também tiveram grande influência na redução dos custos, o que demonstra, respectivamente, a importância de se utilizar máquinas de alta capacidade de trabalho e a importância do bom gerenciamento da operação, no sentido da diminuição dos tempos perdidos e de manutenção e, em conseqüencia, na redução dos custos de recuperação do palhiço.

\section{CONCLUSÕES}

1. O sistema Integral apresentou menor custo total, seguido dos sistemas Picado a Granel, Fardo Cilíndrico, Fardo algodoeiro, Peletizado e Briquetado.

2. No sistema Integral os custos fixos e variáveis acabam sendo rateados entre a cana e o palhiço, com aproveitamento da frota já utilizada para a cana, a qual se encontra atualmente otimizada, em termos de gerenciamento, tecnologia e manutenção.
3. A briquetadora e a peletizadora conseguem o maior grau de compactação entre os sistemas analisados, mas a baixa capacidade da operação de adensamento e sua alta demanda por energia, elevam o custo final da recuperação do palhiço.

4. Em uma mesma agroindústria que não disponha de planta de limpeza a seco pode ser recomendável a co-existência do sistema de fardo cilíndrico, juntamente com o sistema Picado a Granel, sendo que o primeiro seria utilizado em distâncias acima de $30 \mathrm{~km}$ e o segundo nas distâncias menores.

5. Os fatores que mais influenciaram o custo de recolhimento do palhiço para os sistemas analisados são em ordem decrescente: a jornada de trabalho, a eficiência global da operação, o valor de aquisição dos equipamentos e o consumo de combustível.

\section{LITERATURA CITADA}

CONTRAN - Conselho Nacional de Trânsito. Estabelece os limites de peso e dimensões para veículos que transitem por vias terrestres. Resolução no. 12, de 06 de setembro de 1998. Diário Oficial, Brasilia.

COPERSUCAR - Cooperativa de Produtores de Cana-deAçúcar, Açúcar e Álcool do Estado de São Paulo. Seminário Sobre Bagaço de Cana, 1983, Piracicaba. Anais... Piracicaba: COPERSUCAR, 1983. 32p.

Eriksson, S.; Prior, M. The briquetting of agricultural wastes for fuel. Rome: Food and Agriculture Organization of the United Nations, 1990. 208p.

Fernandes, A. C. Cálculos na agroindústria da cana-de-açúcar. Piracicaba: STAB. 2000.193p.

Goldembrg, J.; Coelho, S. T. Present status of biomass use in Brazil. In: International Seminar USP-Petrobrás on Biomass for Energy Production. 2000, São Paulo. Anais... São Paulo: COPERSUCAR, 2000. 49p.

Ideanews. Com maior densidade. Revista Ideanews, Ribeirão Preto: Grupo Gráfico São Francisco, ano 3, n.19, p.28-31, 2002.

Leon, M. J. Avaliação de desempenho operacional de duas colhedoras em cana (Saccharum ssp.) crua. Piracicaba: ESALQ/USP, 2000. 112p. Dissertação Mestrado

Lopes, M. B. Simulação de um sistema de carregamento e transporte de cana-de-açúcar. Piracicaba: ESALQ/USP, 1995. 143p. Tese Doutorado

Macedo, I. C.; Cortez, L. A. B. Sugar-cane industrial processing in Brazil. In: Rosillo-Calle, F.; Bajay, S. V.; Rothman, H. (ed.). Industrial uses of biomass energy. London: TaylorFrancis, 2000. p.140-154.

Nery, M. S. Desempenho operacional e econômico de uma colhedora em cana crua. Piracicaba: ESALQ/USP, 2000. 108p. Dissertação Mestrado

Nuñez Gago; J. S. Corte, carregamento e transporte de canade-açúcar: comparação de sistemas alternativos. In: Seminário de Tecnologia Agronômica, 3, 1986, Piracicaba. Anais... São Paulo: COPERSUCAR, 1986. p.489-522.

Ripoli, M.L.C. Mapeamento do palhiço enfardado de cana-deaçúcar (Saccharum spp.) e do seu potencial energético. Piracicaba: ESALQ/USP, 2002. 91p. Dissertação Mestrado 
Ripoli, T. C. C.; Ripoli, M. L. C. Biomassa de cana-de-açúcar: Colheita, energia e ambiente. Piracicaba: Ripoli, T. C. C., 2004. 302p.

Schembri, M. G; Hobson, P. A.; Paddock, R. The development of a prototype factory-based trash separation plant. Proceedings-Australian Society of Sugar Cane Technologists, v.24, p. 12-18, 2002.
UNICA - União da Indústria de Cana-de-Açucar. Início da produção no Centro-Sul. Boletim UNICA. São Paulo: UNICA, ano 6, n.52, p.1, 2003.

Wood, J.; Hall, D. O. Bioenergy for development: technical and environment dimensions. Rome: FAO, 1995. 300p. 